\title{
NOTAS INFORMATIVAS
}




\section{Revista Ciencias Espaciales, instrucciones a los autores y criterios para el diseño, diagramación y maquetación}

\section{POLÍTICA EDITORIAL}

La Revista Ciencias Espaciales es una publicación semestral de la Facultad de Ciencias Espaciales de la Universidad Nacional Autónoma de Honduras. Cada año calendario se publica un Volumen que consta de dos Números. El primero, Numero 1, llamado Primavera, incluye artículos de los campos de Astronomía y Astrofísica, Ciencia y Tecnologías de la Información Geográfica, Arqueoastronomía y Astronomía Cultural y Ciencias Aeronáuticas. El segundo, el Numero 2, llamado Otoño, se dedica rotativamente por años, a cada uno de los campos temáticos mencionados. El color de fondo de la carátula de la Revista cambia anualmente de: azul espacio para Astronomía y Astrofísica, verde tierra para Ciencia y Tecnologías de la Información Geográfica, rojo ladrillo para Arqueoastronomía y Astronomía Cultural, azul cielo para Ciencias Aeronáuticas.

La Revista Ciencias Espaciales tiene un Director y, un Consejo Editorial integrado por profesores de los Departamentos de la Facultad y otros Profesores invitados. Ellos son los encargados de recibir los documentos y gestionar el proceso de selección de los artículos, edición y publicación de la Revista. Dependiendo del campo temático del año, rotatoriamente un miembro del Consejo Editorial se desempeña como Editor de la Revista. La Revista Ciencias Espaciales cuenta además con un Consejo Científico Internacional responsable de velar por la calidad del contenido de la Revista. En el interior de la Portada se publican los nombres del Director, Editor, Miembros del Consejo Editorial y del Consejo Científico.

La Revista Ciencias Espaciales publica artículos originales de autores nacionales y extranjeros, residentes dentro o fuera del país. Los artículos publicados pueden estar referidos a investigaciones científicas en los campos de la Astronomía y 
Astrofísica, Ciencia y Tecnologías de la Información Geográfica, Arqueoastronomía y Astronomía Cultural y Ciencias Aeronáuticas. El contenido de cada artículo es responsabilidad de sus autores. Los artículos no deben exceder las 10,000 palabras incluyendo el resumen, el texto y las referencias bibliográficas citadas.

Los editores se reservan el derecho de rechazar o devolver para su revisión, cualquier artículo que no se considere completo o apropiado. Antes de que un artículo sea publicado, sus autores deben mostrar evidencias de contar con los permisos para hacer citas o usar figuras y datos. Si un artículo tiene varios autores, debe presentarse evidencia que todos los coautores desean publicarlo.

\section{INSTRUCCIONES A LOS AUTORES}

\subsection{Para los Editores}

Los manuscritos son evaluados por los editores en consulta con pares revisores 0 por los especialistas seleccionados. En ocasiones, los autores pueden sugerir revisores. Los editores garantizan el anonimato de los revisores. Los editores tienen la decisión final sobre los manuscritos. El proceso de evaluación toma de cuatro a ocho semanas. Los autores son informados de la aceptación o no aceptación de su manuscrito. La aceptación puede indicar mejoras al manuscrito. Los documentos no aceptados, pueden ser considerados después de revisados, para una nueva selección.

\subsection{Para los Autores}

Los autores son responsables de los contenidos de sus artículos, y de garantizar que sus documentos se presenten en la forma adecuada, incluyendo los permisos necesarios para agregar figuras, tablas, u otro material protegido.

Cada artículo que se remita para ser publicado en la Revista Ciencias Espaciales debe organizarse en secciones. Todas las secciones deben escribirse a doble espacio y en página separada. El orden de las secciones es el siguiente:

- Página del Título (página separada, numerada como página 1)

- Resumen en idioma español (en página separada) 
- Resumen en idioma Inglés (en página separada)

- El texto (empieza en página separada)

- Agradecimientos (se incluyen inmediatamente al final de texto)

- Referencias citadas (empiezan en una nueva página)

- Figuras (en página separada cada una)

- Tablas (en página separada cada una)

\subsubsection{Página del Título}

Esta página debe incluir:

- El título del artículo. Escrito en mayúsculas, centrado y colocado en la parte superior de la página. El título debe ser conciso, pero informativo. Su objetivo es dar a conocer al lector lo esencial del artículo. No debe exceder de 15 palabras.

- Nombre del autor o los autores. Escribir el nombre completo del autor o autores, indicando el nombre del departamento, institución o instituciones a las que pertenecen.

- Debe indicarse también la dirección electrónica y el teléfono del autor principal responsable de la correspondencia a la que pueden dirigirse avisos sobre el artículo.

\subsubsection{Página de Resumen en idioma español}

Debe incluirse un Resumen en idioma español, con las siguientes características:

- Debe tener un máximo de 250 palabras.

- La estructura debe contener el objetivo del estudio; metodología, técnicas o procedimientos básicos utilizados; los resultados más destacados y las principales conclusiones. Hará hincapié en aquellos aspectos del estudio o de las observaciones que resulten más novedosas o de mayor importancia.

- Con el encabezado de Palabras clave, inmediatamente después del Resumen se deben incluir de 3 a 5 palabras clave las cuales facilitaran el indizado del artículo.

\subsubsection{Página de Resumen en idioma inglés}

Un Resumen y palabras clave también deben ser presentados escritos en idioma inglés. El resumen en inglés puede ser un poco mayor de 250 palabras. 


\subsubsection{El Texto}

Al inicio de cada sección, los títulos de primer nivel deben escribirse en letras mayúsculas y negritas. Los títulos de segundo nivel deben escribirse en mayúsculas y minúsculas, en negritas. Los títulos de tercer nivel, deben escribirse en mayúsculas y minúsculas, y en letra cursiva.

Se recomienda que el texto se estructure en las siguientes secciones: Introducción, Metodología, Resultados, Discusión y Conclusiones.

Introducción. La finalidad de esta sección es ubicar al lector en el contexto en que se realizó la investigación, por lo que debe mencionar claramente los siguientes aspectos:

- El propósito o finalidad de la investigación: es importante que quede claro cuál ha sido el problema estudiado, y cuál es la utilidad del producto de la investigación (para que sirve, a quien le sirve, donde se puede usar, etc.)

- Se debe enunciar de forma resumida la justificación del estudio.

- Los autores deben aclarar que partes del artículo representan contribuciones propias y cuales corresponden a otros investigadores, incluyendo en estos casos las referencias bibliográficas apropiadas.

- En esta sección se describirá de manera muy general la metodología empleada, resultados y las conclusiones más importantes del trabajo.

- Se pueden enunciar los retos que conllevó la realización de la investigación y una explicación breve de cómo se superaron.

Metodología. En términos generales, es la manera estructurada por medio de la cual se ha logrado obtener conocimiento o información producto de la investigación. En términos prácticos, es la manera seleccionada para solucionar el problema estudiado.

Aquí se describe el diseño del método o del experimento (aleatorio, controlado, casos y controles, prospectivo, etc.). Se indicará con claridad cómo y por qué se realizó el estudio de una manera determinada. Se ha de especificar cuidadosamente el significado de los términos utilizados y detallar de forma exacta como se recogieron los datos. Estos métodos se describirán también en el resumen del artículo. 
Se describe el área de estudio, población u objetos sobre los que se ha hecho la investigación. Describe el marco y como se ha hecho su selección. Describe con claridad cómo fueron selecciónalos los sujetos, objetos o elementos sometidos a observación.

Se indica el entorno donde se ha hecho el estudio. Procure caracterizar el lugar o ubicación escogida.

Se describen las técnicas, tratamientos (siempre utilizar nombres genéricos), mediciones y unidades, pruebas piloto, aparatos y tecnología, etc. Describa los métodos, aparatos y procedimientos empleados con el suficiente grado de detalle para que otros investigadores puedan reproducir los resultados.

Resultados. Presente los resultados auxiliándose de tablas y figuras, siguiendo una secuencia lógica. No repita en el texto los datos de las tablas y figuras; destaque o resuma tan solo las observaciones más importantes. Recuerde que las tablas y figuras deben tener una numeración correlativa y siempre deben estar referidos en el texto.

Los resultados deben ser enunciados claros, concretos y comprensibles para el lector; y por supuesto, se deben desprender del proceso investigativo enmarcado en el artículo.

Discusión. Haga hincapié en aquellos aspectos nuevos e importantes del estudio y en las conclusiones que se derivan de ellos. No debe repetir, de forma detallada, los datos u otras informaciones ya incluidas en los apartados, las limitaciones del estudio, así como sus implicaciones en futuras investigaciones. Si es posible se compararan las observaciones realizadas con las de otros estudios pertinentes.

Conclusiones. Son proposiciones o ideas producto o resultado de la investigación realizada, de modo que se deben relacionar con los objetivos del estudio. Evite afirmaciones poco fundamentadas o subjetivas y conclusiones insuficientes avaladas por los datos.

Agradecimientos. Los agradecimientos se incluyen al final del texto. Este debe ser un apartado muy breve, en donde se agradece a las personas que han colaborado 
con la investigación, o a las instituciones que apoyaron el desarrollo del trabajo. También se puede incluir en los agradecimientos el apoyo financiero y los medios materiales recibidos.

\subsubsection{Referencias citadas}

La lista de las referencias citadas y las citas deben concordar y ser precisas. Todas las referencias que aparecen citadas en el texto deben de aparecer también en la lista de referencias; y todas las referencias listadas deben de aparecer mencionadas en el texto.

Las referencias deben ser utilizadas en el texto incluyendo el apellido del autor y el año de la publicación. Para construir la lista de referencias se recomienda utilizar las Normas Internacionales APA, distinguiendo si la cita se refiere a un solo autor 0 a varios autores de un artículo, al autor de un libro, sección o capítulo de un libro, una publicación periódica u otra obtenida en Internet. En tal sentido, es necesario incluir todas las fuentes que sustentan la investigación realizada y que se usaron directamente en el trabajo.

\subsubsection{Figuras}

Después de las Referencias Citadas, en páginas separadas se incluyen las figuras. Para las figuras tener en cuenta que:

- Todas las figuras deben ser mencionadas explícitamente en el texto por sus números.

- Las figuras se numeraran consecutivamente según su primera mención el texto, desde la primera hasta la última. El formato, letras, números y símbolos usados en las figuras, serán claros y uniformes en todos los lugares donde aparezcan en el artículo.

- Los títulos y las explicaciones detalladas se incluirán en las leyendas de las figuras y no en las mismas figuras.

- Si se emplean fotografías de personas, figuras o imágenes que no son de elaboración propia, se deberá incluir el permiso por escrito para poder utilizarlas.

- Todas las figuras, fotografías e ilustraciones deben tener un pie de imagen que las identifique. 
- En figuras múltiples, la leyenda debe describir las componentes de la figura: (a), (b), (c), etc., las cuales deben estar claramente etiquetadas.

En el Texto, en un renglón separado escribir "Incluir Figura XX", para indicar el lugar recomendado para insertar la Figura. En la edición final de la Revista, la Figura se insertará, lo más cercano inmediatamente al lugar que fue citada.

\subsubsection{Tablas}

Después de las Figuras, en páginas separadas incluya las Tablas. Tomar en cuenta que:

- Todas las tablas deben ser mencionadas explícitamente por sus números y deben aparecer en el orden correcto en el texto del documento. Una tabla con un número mayor no debe anteceder a otra con número menor (por ejemplo: tabla 4 antes que tabla 3 ).

- Las tablas se enumeran correlativamente desde la primera hasta la última. Cada tabla debe ser enunciada en el texto por lo menos una vez.

- A cada tabla debe asignársele un breve título, pero no dentro de ésta. Las tablas deben ser escritas en líneas horizontales, y no deben dejarse filas en blanco entre ellas. Los encabezados de las columnas deben ser muy breves, con la primera letra en mayúscula. En estos encabezados, las unidades deben aparecer inmediatamente debajo.

- Las explicaciones o información adicional se pondrán en notas al pie de tabla, no en la última fila de la tabla. En estas notas se especificaran las abreviaturas empleadas, para hacerlo se usaran como llamadas.

- Identifique las unidades de medida utilizadas.

- Las tablas no deben presentarse divididas en partes. A tablas relacionadas debe asignárseles números diferentes, manteniendo la secuencia correspondiente.

- Las tablas de los apéndices deben numerarse en una nueva secuencia.

- Todas las referencias citadas en las tablas deben aparecer en la lista de referencias citadas.

En el Texto, en un renglón separado escribir "Incluir Tabla XX", para indicar el lugar recomendado para insertar la tabla. En la edición final de la Revista, la tabla se insertará, lo más cercano inmediatamente al lugar que fue citada. 


\subsubsection{Unidades de medida}

Las unidades de medida se deben expresar en unidades del sistema métrico decimal. Se debe tomar como referencia el Sistema Internacional de Unidades.

\subsubsection{Abreviaturas y símbolos}

En las siglas, abreviaturas y símbolos, use únicamente las normalizadas. Evite las abreviaturas en el Titulo y en el Resumen. Cuando en el texto se emplee por primera vez una abreviatura o sigla, esta debe ir precedida del término completo, salvo si se trata de una unidad de medida común.

\subsubsection{Recomendaciones generales para presentar el manuscrito}

Para presentar el manuscrito, se recomienda al autor o autores tener en cuenta:

- Todo el manuscrito debe presentarse en un solo documento, escrito con letra Arial Narrow, tamaño 12.

- Las páginas se numeran consecutivamente comenzando por la página del título hasta terminar con la última referencia citada.

- El número de página se ubicara en ángulo inferior derecho de cada página.

- Todo el documento se imprimirá en papel blanco tamaño carta, con márgenes de $2 \mathrm{~cm}$ a cada lado (superior, inferior, derecho e izquierdo). El papel se imprimirá en una sola cara.

- La extensión total del texto tendrá un máximo de 17 páginas, a doble espacio, incluidas desde la página del título hasta las referencias citadas.

- Las figuras deben presentarse con la mayor resolución posible (mínimo 300 psi), en un formato JPG o TIFF, una figura por cada página.

- Incluya las autorizaciones para la reproducción de material anteriormente publicado, para la utilización de figuras o ilustraciones que puedan identificar a personas o para imágenes que tengan derechos de autor. Adjunte la cesión de los derechos de autor y formularios pertinentes.

- Las tablas deben presentarse, una tabla por página.

- Los autores deben entregar el manuscrito en un soporte electrónico (en CDROM, memoria o correo electrónico). Para la entrega tener en cuenta las siguientes consideraciones: a) Especificar claramente el nombre del archivo que contiene el artículo; b) Etiquetar el CD, memoria o el correo electrónico, con el 
nombre abreviado del artículo y del autor; c) Facilitar la información sobre el software y hardware utilizado, si procede; d) Indicar el nombre del autor responsable a quien puede dirigirse avisos sobre el artículo.

\section{CRITERIOS PARA EL DISEÑO, DIAGRAMACIÓN Y MAQUETACIÓN DE LARE- VISTA}

\section{De la Portada:}

Texto:

- Ciencias Espaciales. Tipo: Times New Roman. Tamaño: 48. Color: blanco.

- Publicación semestral de la Facultad de Ciencias Espaciales (FACES)

- Universidad Nacional Autónoma de Honduras.

- Volumen, Año, Número, Temporada.

- ISSN:2225-5249

- URL: http://www.faces.unah.edu.hn

Imágenes y Logos:

- Logo de la UNAH

- Imagen alusiva al contenido

Color de fondo:

- Revista Ciencias Espaciales de Astronomía y Astrofísica: Azul Espacio. R:41, $\mathrm{G}: 52, \mathrm{~B}: 82$

- Revista Ciencias Espaciales de Ciencia y Tecnologías de la Información Geográfica: Verde Tierra R:37, G:107, B:44

- Revista Ciencias Espaciales de Arqueoastronomía y Astronomía Cultural: R:130, G:47, B:44

- Revista Ciencias Espaciales de Ciencias Aeronáuticas: Azul Cielo. R:160, G:199, B:230

Dimensiones:

- $24.4 \times 16 \mathrm{~cm}$. Grosor varia 


\section{Del Lomo}

Texto:

- Ciencias Espaciales. Tipo: Times New Roman. Tamaño: 12, Color: Blanco.

- Volumen x, Año xxxx, Número x, Temporada xxxxxx.

\section{De la contraportada:}

Imágenes y logos:

- UNAH

- Facultad de Ciencias Espaciales

\section{Del interior de la Revista}

Texto:

- $\quad$ Tipo de letra: Arial Narrow. Tamaño:12

- Espaciado: Anterior 0 puntos. Posterior 10 puntos. Interlineado: mínimo.

- Márgenes: superior: 0.8 pulgadas, izquierdo: 0.8 pulgadas, inferior: 1 pulgada, derecho: 0.5 pulgadas.

- Figuras: Tipo de letra: Arial Narrow. Tamaño: 12

Las páginas de la derecha deben llevar:

- En la parte superior: Revista Ciencias Espaciales, Volumen x, Año xxxx, Numero $x$, Temporada xxxxxxx,

- En la parte inferior: Facultad de Ciencias Espaciales y el número de la página.

Las páginas de la izquierda deben llevar:

- En la parte superior: Revista Ciencias Espaciales, Volumen x, Año xxxx, Número x, Temporada xxxxxxx.

- En la parte inferior: Facultad de Ciencias Espaciales y el número de página.

El arte y diagramación de la Revista Ciencias Espaciales es aprobado por la Secretaria Ejecutiva de Desarrollo Institucional de la UNAH y la Editorial Universitaria. Las dimensiones de cada ejemplar son de 23.4 × $16 \mathrm{~cm}$.

Fecha de última actualización: Julio de 2016. 
